\title{
A Study on Optimized Size of a Mobile Harbor for South Korea Coastal Service
}

\author{
† Heo, Sung-Kuk $\cdot *$ Park, Nam-Kyu \\ + Tongmyong University, Yondangdong 535, Namgu, Busan, Korea \\ *Tongmyong University, Yondangdong 535, Namgu, Busan, Korea
}

\begin{abstract}
The aim of paper is to calculate the optimized size of Mobile Harbor(MH) which would be operated in South Korea coast area. $M H$ is the combined entity which has the function of both ship and container port. In estimating the optimized size, the total cost concept is applied to the different size of MH. Trade-off factors for calculating total cost are MH cost and the over-capacity lost cost. The factors for MH cost estimation are the cargo demand, distance from origin to destination, voyage route and MH's fixed and variable cost in both sailing and port. The other cost is the over-capacity lost cost which is occurred from dead space in case of oversize compared with a voyage demand. The alternatives for the least cost are 250TEU, 500TEU, 750TEU and 1,000TEU sized vessel. The result of research is that 250TEU sized vessel is optimized in a South Korea costal service. If the coastal area be separated in terms of voyage distance or the specific area in considering trade, the optimized size is changed depending upon distance.
\end{abstract}

Key words : Mobile Harbor, Optimized size, over-capacity lost cost, fixed cost, variable cost

\section{Introduction}

Mobile Harbor(MH) has the dual function of sea transportation and container handling armed with high mechanical and systematic technology. As technical specification of Mobile Harbor, it has 8 to 15 knots speed, 250TEU laden capacity, 4 meters draft, 92 meters LOA, 26 meters breadth, 30 moves handling rate capacity per hour-ship. Depending on trade where MH plies, the optimal size of MH can be decided. The aim on the paper is to estimate the optimized size of $\mathrm{MH}$ which would be operated in South Korea coast area.

Mobile Harbor has strong point which is used for cross docking by which mother ship cooperates with $\mathrm{MH}$ in handling containers using cranes. As the trait of $\mathrm{MH}$ which has cranes and low draft, it can access the general cargo berth without container handling equipment or low depth channel. In reality, coastal shipping in Korean peninsula is not well developed due to short distance. Several steps and long transit time between origin and destination are main reason for under developed coastal shipping. In the difficulty of expanding coastal shipping in Korea, MH can be emerged as an alternative of modal shift from road to sea. Under the boundary of costal transportation with $\mathrm{MH}$, the estimation of $\mathrm{MH}$ optimal size is prerequisite for designing and building.

This paper is to calculate the optimized size of $\mathrm{MH}$ which would be operated in South Korea coast area. In estimating the optimized size, the total cost concept is applied to the different size of $\mathrm{MH}$. Two different costs of $\mathrm{MH}$ cost and the lost sales cost can be selected for estimating total cost. The several factors for $\mathrm{MH}$ cost are to be considered. Those are the cargo demand and distance from origin to destination, voyage route and $\mathrm{MH}^{\prime} \mathrm{s}$ fixed and variable cost in both sailing and port. The other cost is the over -capacity lost sales cost which is occurred from dead space in case of oversize compared with a voyage demand.

\section{METHODOLOGY}

The optimized size of $\mathrm{MH}$ in Korea costal area can be suggested with total cost concept. Total cost consists of ship operating cost and over-capacity lost cost which has trade off relationship. Ship operation cost is divided into variable cost and fixed cost. The variable cost as occurred in activity consists of the bunker cost and the port charges and dues when entering the port for loading and unloading. The fixed cost is called running cost which is the preparing cost for navigation regardless in navigating or in port or at lay up. As the items of running cost, depreciation cost, capital cost, ship store cost, repair cost, insurance cost and crew cost are included in the cost category. The fixed cost can be measured on yearly basis. Although there are some

\footnotetext{
† Corresponding author, globalko@kornet.net 051)464-2280

* nkpark@tu.ac.kr 051)629-1861
} 
arguments about the classification of individual cost into variable or fixed cost (Mcconville, J., 1999, Branch, A.E., 2007), this paper follows Drewry classification based on usual practice.

The over-capacity lost cost has relationship between ship size and demand per voyage. If ship' $s$ capacity is oversized than cargo volume per voyage, the shipping company has missed shipping freight equivalent to dead space. Theoretically speaking, bigger ship tends to enjoy lower unit cost than that of small ship due to the effect of fixed cost spreading. However, big ship has experienced some difficulties in terms of dead space which is occurred by shipping demand shortage, the performance of crane facilities, the time window of river channel by ebb tide which enables ship passing through without hindering for full day, and berth windows due to over draught.

As a consequence, it is obvious that optimal size is to consider not only shipping cost, but also over-capacity lost cost which is the missed revenue for over sized capacity. As optimal size is the function of total cost which is the sum of shipping cost and over-capacity lost cost, U shaped graph can be drawn as Fig. 1.

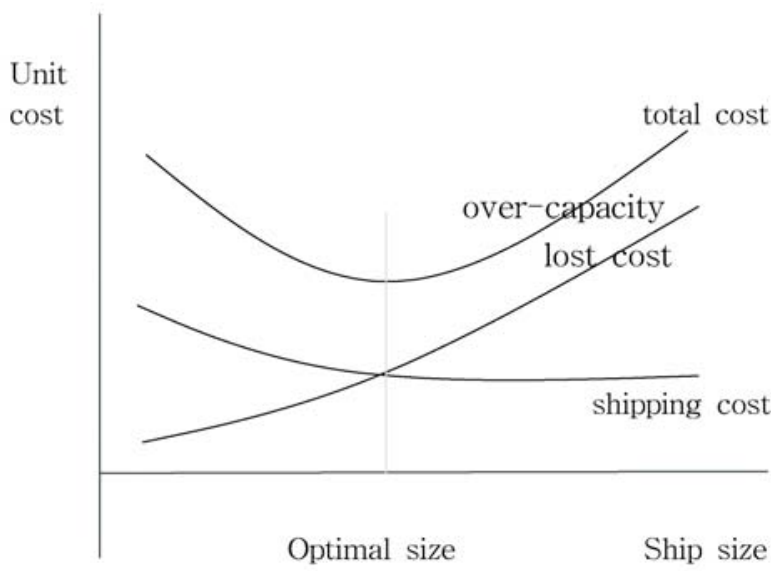

Fig. 1 Total cost concept for optimal size

For calculating the total cost, the optimization formula with minimum total cost is to be developed. As early mentioned, total cost consists of shipping cost and over-capacity lost cost. The former consists of running cost as fixed cost, bunker cost, port charges and dues as variable cost. Before solving the optimal size problem, quantity model for total cost is to be designed, then voyage routes from origin port to destination port are set up in considering route distance, derived demand volume occurred from hinterland industry. In designing route, 10 ports such as Pohan, Ulsan, Masan etc. among 27 trading ports in
Korea, are selected in considering of hinterland industry. In the model, the number of voyage routes is defined as $M$ and daily running cost is defined Hc. The bunker cost per ton is defined $\mathrm{Bc}$, and daily bunker consumption in navigation and in port is defined $\mathrm{Fm}$ and $\mathrm{Fp}$ each. Navigation time and port time in hour unit is defined Tm and Tp. According to above definition, daily bunker cost in navigation is calculated $\mathrm{Bc} \times(\mathrm{Fm} \times \mathrm{Tm})$, and bunker cost in port is calculated $\mathrm{Bc} \times(\mathrm{Fp} \times \mathrm{Tp})$. Daily port dues, berthingicharge, cargo handling charge and line handling per voyage are defined Pc, Mc, Cc and Lc. Based on above definition, daily port charges per voyage can be modeled $(\mathrm{Pc}+\mathrm{Mc}+\mathrm{Cc}+\mathrm{Lc}) \times \mathrm{T}$. Three types of cost being summed and being divided by decision variable $G$ and the number of voyage, the consequence will be the total cost of shipping per unit and route.

Last component of total cost is over-capacity lost cost defined $C_{l}$. This cost is restricted within the lost revenue occurred by dead space. As MH's draught is under $5 \mathrm{~m}$, the channel depth and berth time windows is not to be considered in the $C_{l}$ definition.

$$
\begin{aligned}
M \text { Min } T_{c}= & \frac{\sum_{m=1}^{M}\left\{H_{c}+B_{c}\left[\left(F_{m} \times T_{m}\right)+\left(F_{p} \times T_{p}\right)\right]+\left[\left(P_{c}+M_{c}+C_{c}+L_{c}\right) \times T_{p}\right]\right\}}{G \times M} \\
& \quad+\frac{\sum_{m=1}^{M} C_{l}}{2 \times G \times M} \\
\text { S.t. } & \\
\text { G, } M & >0
\end{aligned}
$$

$\mathrm{G}$ is decision variable dimension of which is one of 250TEU 500TEU, 750TEU or 1,000TEU capacity of mobile harbor.

$\mathrm{M}$ is 14 routes as adapted on table 3.

\begin{tabular}{|l|c|c|}
\hline MH Size (TEU) & 250TEU & 500TEU \\
\hline LOA (meter) & 92 & 118 \\
\hline Gross Tonnage & 2,468 & 7,506 \\
\hline Deadweight & 4,386 & 8,726 \\
\hline Draft (meter) & 5 & 6 \\
\hline & \\
& \\
&
\end{tabular}




\begin{tabular}{|c|c|}
\hline 750 TEU & 1,000 TEU \\
\hline 144 & 169 \\
\hline 13,379 & 16,731 \\
\hline 16,640 & 22,740 \\
\hline 8 & 9 \\
\hline \\
\hline
\end{tabular}

Fig. 2 Specification of $\mathrm{MH}$ on capacity

\section{DATA COLLECTION AND ANALYSIS}

New shipbuilding cost of Mobile Harbor of which size is 250TEU is estimated US\$ 30,000,000 by Korean ship builder (KAIST, 2009). The cost is 2 times higher than that of feeder ship in equivalent size (Drewry, 2008). As the cost of others including 500TEU, 750TEU and 1,000TEU is not informed, the estimation is tried by the ratio based on feeder' s new building cost of equivalent size.

The running cost which is fixed regardless of voyage consists of ship depreciation cost, ship store cost, lubricating cost, water supply cost, ship repair cost, manning cost, capital cost, general overhead cost (Table 1).

Table $1 \mathrm{MH}^{\prime}$ s running cost

\begin{tabular}{|l|c|}
\hline MH Size (TEU) & 250TEU \\
\hline Ship Building Cost (US \$) & $30,000,000$ \\
\hline Yearly Running Cost (US \$) & $5,961,217$ \\
\hline Daily Running Cost (US \$) & 16,332 \\
\hline
\end{tabular}

\begin{tabular}{|r|r|r|}
\hline $500 \mathrm{TEU}$ & $750 \mathrm{TEU}$ & $1,000 \mathrm{TEU}$ \\
\hline $38,400,000$ & $46,800,000$ & $55,200,000$ \\
\hline $7,291,352$ & $8,621,486$ & $9,951,621$ \\
\hline 19,976 & 23,621 & 27,265 \\
\hline
\end{tabular}

Variable cost consists of port dues and charges and bunker cost in port and in navigation. As $\mathrm{MH}$ is mainly operated within a harbor or between domestic harbors, port dues, $\mathrm{MH}$ operator will pay for only $\mathrm{MH}$ berthing charge and line handling charge occurs, but it is assumed that container handling charge will be freed for utilizing own facility.

Table 2 MH's port dues and port charge

\begin{tabular}{|l|c|}
\hline MH Size & 250TEU \\
\hline Port Dues (US\$) & 316 \\
\hline Berthing Charge (US\$) & 84 \\
\hline Cargo Handing(US\$) & 7,500 \\
\hline Line Handling (US\$) & 86 \\
\hline Total of Port Dues and Charges (US\$) & 7,986 \\
\hline
\end{tabular}

\begin{tabular}{|c|c|c|}
\hline $500 \mathrm{TEU}$ & $750 \mathrm{TEU}$ & $1,000 \mathrm{TEU}$ \\
\hline 961 & 1,713 & 2,142 \\
\hline 255 & 455 & 569 \\
\hline 15,000 & 22,500 & 30,000 \\
\hline 86 & 86 & 86 \\
\hline 16,302 & 24,753 & 32,796 \\
\hline
\end{tabular}

In calculation of bunker cost, navigation and port time is to be estimated because ship engine consumes two types of bunker oil of which cost is different in navigation or in port. As voyage time is dependent on the number of entering ports and distance from origin to destination, the voyage route is to be designed first before estimating navigation and port times of $\mathrm{MH}$ and bunker cost. Fourteen routes are developed in considering the frequency of departure, round trip time, calling ports in cluster and cargo demand. Annual cargo demand from the port of Busan to destination port can be drawn from origin destination statistics (Inner Report of MOLM 2009), which shows container flow between sixteen origin cities and provinces to sixteen destinations on land transportation. As statistics is the only official data, it is necessary to allocate $\mathrm{O}-\mathrm{D}$ (Origin and Destination) volume to that of destination port from the port of Busan. First step is to select 10 calling ports from the port of Busan in considering the distance from origin, proximity between ports and hinterland industry. Second step is to apply the assumed ration of $\mathrm{O}-\mathrm{D}$ volume based on Baird research result, that is the future volume of coastal shipping will be average $16 \%$ of total land transportation in Europe(Baird 2007).

In designing routes, the assumed scenario is that mother vessel call at the port of Busan and then the $\mathrm{MH}$ is alongside of mother ship and handles containers for transporting to destination port. Destination ports which do not own the dedicated quay crane facility are selected in elevating the value of $\mathrm{MH}$ function. 
A Study on Optimized Size of a Mobile Harbor for South Korea Coastal Service

Table 3 Route specification from Busan port to final port

\begin{tabular}{|c|l|l|c|}
\hline \multirow{2}{*}{ Route } & \multicolumn{2}{|c|}{ Origin : } & Port of Busan \\
\cline { 2 - 3 } & Calling port & \multicolumn{1}{c|}{ Final Port } & (mile) \\
\hline 1 & & Ulsan & 88 \\
\hline 2 & & Pohang & 208 \\
\hline 3 & Ulsan & Pohang & 227 \\
\hline 4 & & Masan & 87 \\
\hline 5 & & Tongyoung & 99 \\
\hline 6 & Masan & Tongyoung & 119 \\
\hline 7 & & Kwangyang & 216 \\
\hline 8 & & Wando & 310 \\
\hline 9 & Kwangyang & Wando & 375 \\
\hline 10 & & Gunsan & 650 \\
\hline 11 & & Boryung & 707 \\
\hline 12 & Gunsan & Boryung & 716 \\
\hline 13 & & Pyungtak & 850 \\
\hline 14 & & Incheon & 870 \\
\hline
\end{tabular}

\begin{tabular}{|c|c|c|c|}
\hline Route & $\begin{array}{c}\text { Navigation } \\
\text { Time (Hour) }\end{array}$ & $\begin{array}{c}\text { Port Time } \\
\text { (Hour) }\end{array}$ & $\begin{array}{c}\text { Demand1) } \\
\text { (TEU) }\end{array}$ \\
\hline 1 & 11.0 & 10.3 & 210 \\
\hline 2 & 26.0 & 13.9 & 290 \\
\hline 3 & 28.4 & 24.2 & 500 \\
\hline 4 & 10.8 & 16.2 & 342 \\
\hline 5 & 12.4 & 16.2 & 342 \\
\hline 6 & 14.9 & 17.2 & 342 \\
\hline 7 & 27.0 & 5.2 & 94 \\
\hline 8 & 38.8 & 6.2 & 94 \\
\hline 9 & 46.9 & 6.2 & 94 \\
\hline 10 & 81.3 & 5.2 & 95 \\
\hline 11 & 88.4 & 4.4 & 76 \\
\hline 12 & 89.5 & 9.6 & 171 \\
\hline 13 & 106.3 & 10.3 & 209 \\
\hline 14 & 108.8 & 4.1 & 70 \\
\hline
\end{tabular}

According to the above route, daily bunker consumption and cost are estimated on each route. Summing the bunker cost, port charges, the total variable cost per voyage on each route can be produced on Table 4 and then daily total cost per voyage after summing the variable and running cost will be shown on Table 4. The cost which is occurred from over sized capacity than the demand volume is called over-capacity lost sale cost. After calculating the difference value between ship capacity and demand volume, the value is multiplied by lost profit. On the case of $\mathrm{MH}$ with

1) Demand by port is derived from official statistics provided by MOLM(2009).
250TEU capacity and 8 knots speed, the daily average total shipping cost is estimated US\$ 77.7 and lost sale cost is US\$ 53.9. Following the same procedure for estimation, daily average shipping cost on route and daily lost cost will be drawn as table 5. In a consequence, daily cost of $\mathrm{MH}$ with 250 TEU and 8 knot speed is drawn as optimal size.

Table 4 Daily total cost on route of $\mathrm{MH}$ with 8 knots speed and 250 TEU capacity

(Unit US \$)

\begin{tabular}{|c|c|c|c|}
\hline Route & $\begin{array}{c}\text { Bunker } \\
\text { Cost in } \\
\text { Navigation }\end{array}$ & $\begin{array}{c}\text { Bunker } \\
\text { Cost in } \\
\text { Port }\end{array}$ & $\begin{array}{c}\text { Port Dues } \\
\text { and } \\
\text { Charges }\end{array}$ \\
\hline 1 & 1,980 & 6,186 & 7,986 \\
\hline 2 & 4,659 & 6,471 & 7,986 \\
\hline 3 & 5,081 & 7,301 & 15,971 \\
\hline 4 & 1,940 & 6,655 & 7,986 \\
\hline 5 & 2,215 & 6,655 & 7,986 \\
\hline 6 & 2,668 & 6,736 & 15,971 \\
\hline 7 & 4,839 & 5,770 & 7,986 \\
\hline 8 & 6,944 & 5,850 & 7,986 \\
\hline 9 & 8,400 & 5,850 & 15,971 \\
\hline 10 & 14,561 & 5,773 & 7,986 \\
\hline 11 & 15,838 & 5,707 & 7,986 \\
\hline 12 & 16,039 & 6,125 & 15,971 \\
\hline 13 & 19,041 & 6,180 & 7,986 \\
\hline 14 & 19,489 & 5,686 & 7,986 \\
\hline \multicolumn{7}{|l|}{ Route Average Daily Cost per TEU } \\
\hline
\end{tabular}

\begin{tabular}{|c|c|c|c|}
\hline $\begin{array}{c}\text { Daily } \\
\text { Variable } \\
\text { Cost }\end{array}$ & $\begin{array}{c}\text { Daily } \\
\text { Running } \\
\text { Cost per } \\
\text { Voyage }\end{array}$ & $\begin{array}{c}\text { Daily Total } \\
\text { Shipping } \\
\text { Cost per } \\
\text { Voyage }\end{array}$ & $\begin{array}{c}\text { Daily lost } \\
\text { and profit by } \\
\text { Over-capacity }\end{array}$ \\
\hline 12,222 & 16,332 & 28,554 & 5,286 \\
\hline 8,531 & 16,332 & 24,863 & $-8,963$ \\
\hline 8,861 & 16,332 & 25,193 & $-79,994$ \\
\hline 9,216 & 16,332 & 25,548 & $-16,463$ \\
\hline 9,047 & 16,332 & 25,379 & $-17,049$ \\
\hline 12,367 & 16,332 & 28,699 & $-18,774$ \\
\hline 11,960 & 16,332 & 28,292 & 24,330 \\
\hline 9,767 & 16,332 & 26,099 & 33,296 \\
\hline 12,255 & 16,332 & 28,587 & 38,594 \\
\hline 7,416 & 16,332 & 23,748 & 59,382 \\
\hline 7,297 & 16,332 & 23,629 & 70,420 \\
\hline 8,423 & 16,332 & 24,755 & 35,992 \\
\hline 6,286 & 16,332 & 22,618 & 21,923 \\
\hline 6,804 & 16,332 & 23,136 & 87,729 \\
\hline Route Average Daily & 114 & 54 \\
Cost per TEU & & & \\
\hline & & & 54 \\
\hline
\end{tabular}


Table 5 Daily total cost per TEU on MH size with 8 knots

\begin{tabular}{|c|c|}
\hline MH Size & 250TEU \\
\hline Daily Shipping Cost per TEU & 102.6 \\
\hline Daily Over-capacity Lost Cost per TEU & 53.9 \\
\hline Daily Total Cost per TEU & 156.5 \\
\hline
\end{tabular}

\begin{tabular}{|c|c|c|}
\hline $500 \mathrm{TEU}$ & $750 \mathrm{TEU}$ & $1000 \mathrm{TEU}$ \\
\hline 71.5 & 57.8 & 55.9 \\
\hline 90.4 & 109.3 & 118.7 \\
\hline 161.9 & 167.0 & 174.6 \\
\hline
\end{tabular}

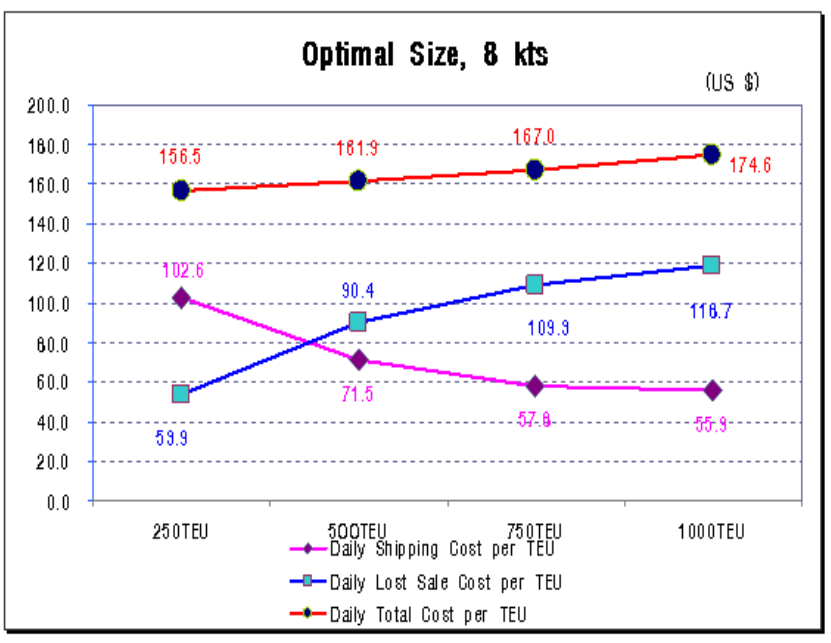

Fig. 3 Optimal size of $\mathrm{MH}$ in keeping $8 \mathrm{kts}$ speed

On second sensitivity analysis, if the speed of $\mathrm{MH}$ is increased to 15 knots, the optimal size would be changed in to 500TEU $~ 750$ TEU capacity.

Table 6 Daily total cost per TEU on MH size with 15 knots

\begin{tabular}{|c|c|c|}
\hline \multicolumn{2}{|c|}{ MH Size (TEU) } & 250TEU \\
\hline \multicolumn{2}{|c|}{ Daily Shipping Cost per TEU } & 116.2 \\
\hline \multicolumn{2}{|c|}{$\begin{array}{c}\text { Daily Over-capacity Lost Cost } \\
\text { per TEU }\end{array}$} & 32.4 \\
\hline \multicolumn{2}{|c|}{ Daily Total Cost per TEU } & 148.6 \\
\hline 500TEU & 750TEU & 1000TEU \\
\hline 83.2 & 68.0 & 66.6 \\
\hline 57.3 & 71.2 & 78.2 \\
\hline 140.5 & 139.3 & 144.8 \\
\hline
\end{tabular}

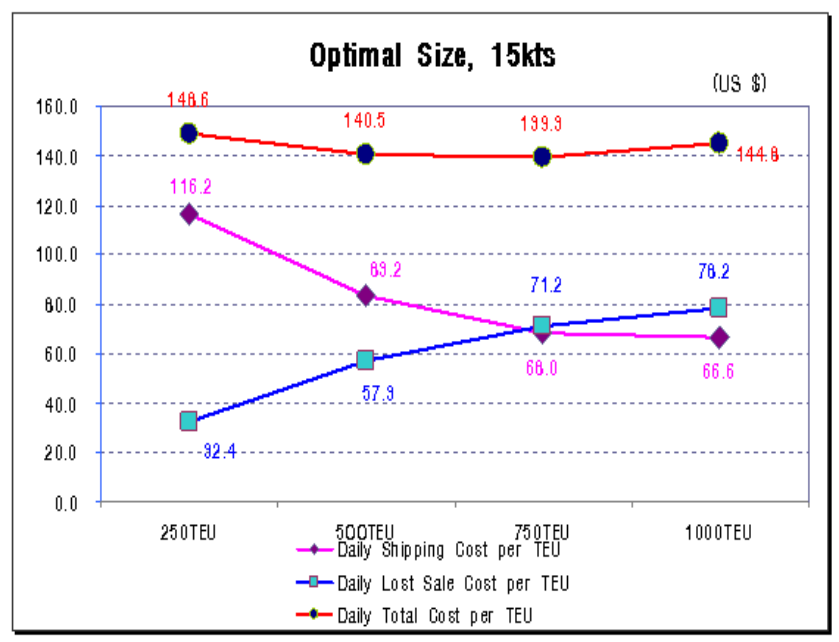

Fig. 4 Optimal size of $\mathrm{MH}$ in keeping $15 \mathrm{kts}$ speed

\section{SENSITIVITY ANALYSIS}

The change of distance from origin to destination gives insights to make optimal size. This session deals with sensitivity of distance variation.

\subsection{Less than 100 mils distance with 8 knots}

If the costal sea distance less than 100 miles is handled for shipping business with $8 \mathrm{kts}$ speed, the optimal size of mobile harbor has $250 \mathrm{TEU}$ laden capacity. As the total cost curve has steep inclination on the figure, 250 laden capacity has dominant position in comparing other size.

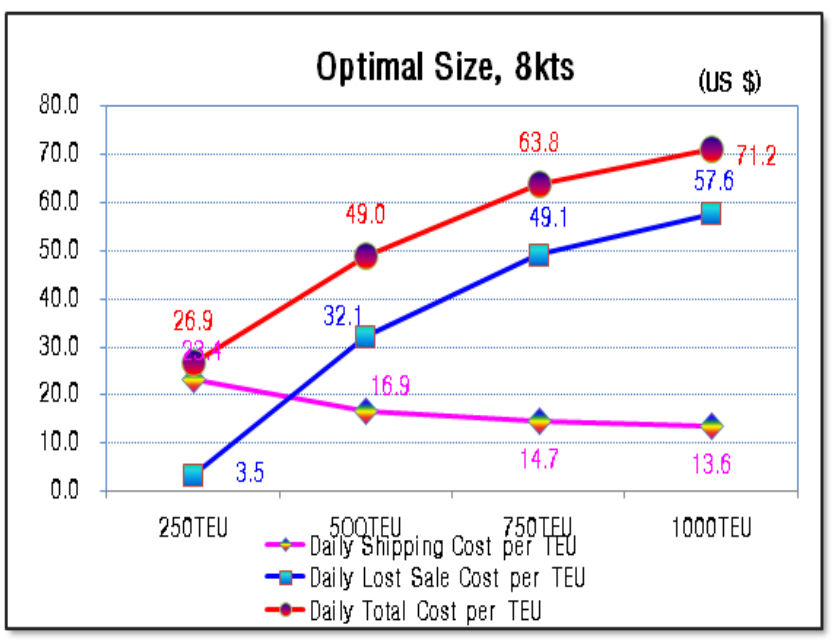

Fig. 5 Optimal size of $\mathrm{MH}$ in keeping 8 kts within 100 n.m. distance

\subsection{Less than 300 miles distance}

If the route distance expanded to more than 100 n.m and 
less than 300 n.m., how the optimal size is changed? The result of analysis is that even if business route is expanded to more than 100 n.m., there is no change in optiamal size. However as it is shown the inclination of curve is more smooth than the case of short distance, 250 TEU laden capacity will lose the dominant position, 500 TEU wil be alternative size ship.

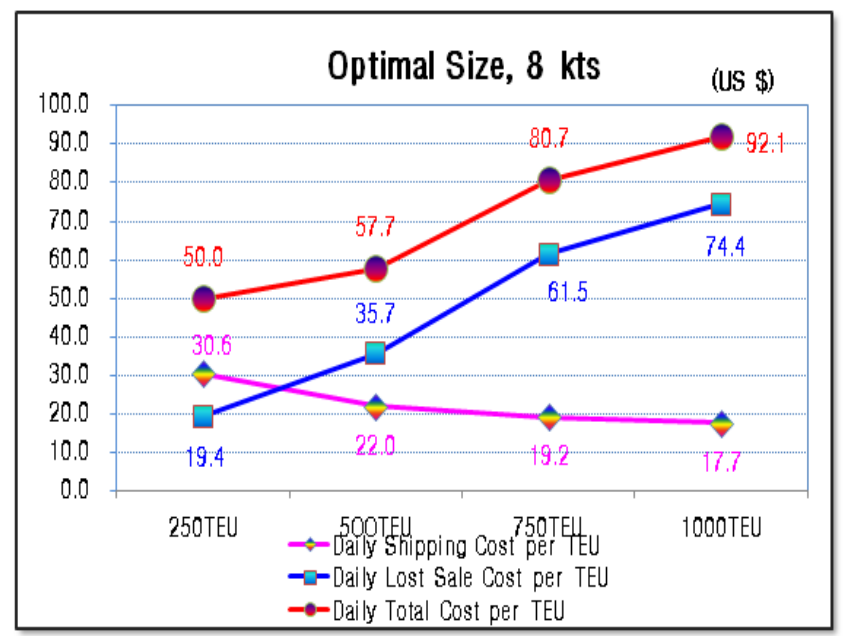

Fig. 6 Optimal size of MH in keeping 8 kts within 100 300 n.m. distance.

\subsection{More than 300 miles distance}

If the route distance expanded to more than 300 n.m., how the optimal size is changed? The result of analysis is that evenif business route is expanded to more than 300 n.m., there is no change in optimal size. This means that optimal size of mobile harbor is strongly impacted from port demand volume.

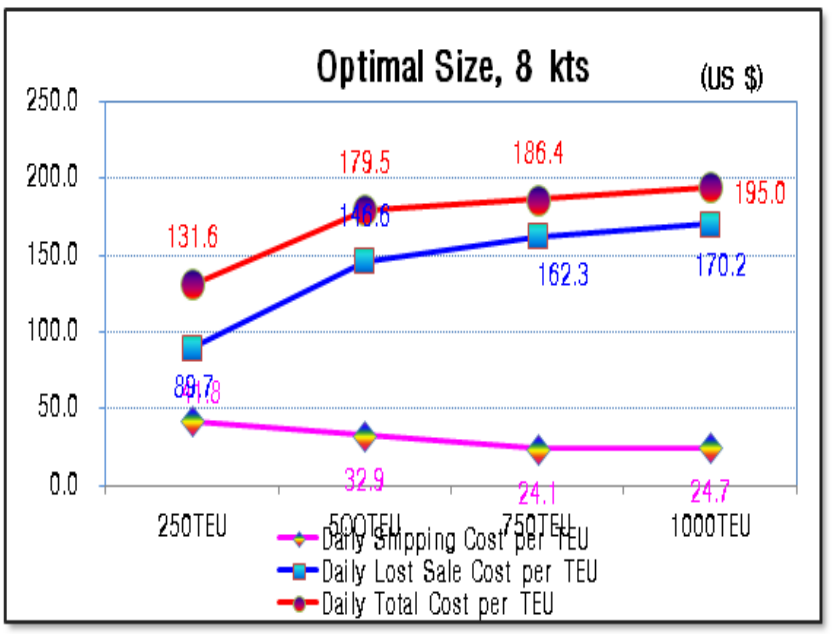

Fig. 7 Optimal size of $\mathrm{MH}$ in keeping 8 kts beyond 300 n.m. distance.

\section{CONCLUSION}

This paper's aim is to identify the optimal size of mobile harbor which is used for the tool of coastal shipping strategy. Due to a mobile harbor having limitation with low speed mobility, the scope of usage is assumed to be restricted on costal or river transportation. Within the coverage, total cost which consists of total shipping cost and oversized-capacity lost sale cost is to be estimated. As the designed specification of $\mathrm{MH}$ is 250TEU laden capacity, 8 knots speed, 30 van handling capacity per hour and 5 meter draft, the quantitative model and rout design on Korea costal area is to be developed for calculating total cost.

In a result, among alternatives of 250TEU, 500TEU, 750TEU and 1,000 TEU, MH with 250TEU capacity is selected as the optimal size. In a sensitivity analysis with increase speed or distance, the speed variable only brings the push up of optimal size.

\section{Acknowledgement}

This research was supported by the MKE(The Ministry of Knowledge Economy), Korea, under the ITRC (Information Technology Research Center) support program supervised by the NIPA(National IT Industry Promotion Agency" (N I PA-2009-C1090-0902-0004)

\section{References}

[1] Adolf Baird, J. Richard Hodgson (2006). Short Sea Shipping on the East Coast of North America: An analysis of opportunities and issues, CanadaDalhousie University. Transportation Planning/Modal Integration Initiative Project ACG-TPMI-AH08 March.

[2] Adolf Baird (2005). Eu Motorways of the sea policy" at European conference on sustainable good $\mathrm{s}$ and passenger transport, Kriistiansand.

[3] Adolf Koi Yu Ng (2009). Competitiveness of short sea shipping and the role of port: the case of North Europe, The journal of Marit. Pol. MGMT Vol.36, No. 4, 337-352.

[4] Adolf Koi Yu Ng and Jeremy K. Y. Kee, 2008, The optimal ship size of container liner feeder services in southeast asia: a ship operator's perspective, Maritime Policy Management, vol. 35, No. 4 353-376

[5] Bojan Beskivnick, M.SC (2006), Importance of short sea shipping and sea motorways in the European and 
Slovenian transport policy, Pomorstvo, god, 20, br 1str. 23-35.

[6] Branch, A.E., 2007, Elements of Shipping, 8th edn (Chelten: Stanley Thorenes)

[7] Containerisation International (2007), Year Book 2007.

[8] Drewry (2008). Annual Container Market Review and Forecast(2007/2008).

[9] Goksel Tenekecioglu (2004). Increasing Intermodal transportation in Europe through Realizing the Value of Short Sea Shipping.

[10] KAIST(2009), Inner Report of MH cost.

[11] KMI (2003). Economic Feasibility Study in Port Development, Research Report of KMI, p. 46.

[12] Mary R. Brooks (2009). Short sea developments in Europe: lessons for Canada, North America Centre for Transborder Studies in Arizona state university No. 10.

[13] Market Shares (2005). Maritime Economics \& Logistics, Vol 7, No 4.

[14] Mconville, J., 1999, Economics of Maritime Transport: Theory and Practice (London: Withby)

[15] MOLM(2009), Inner Report of O-D volume.

[16] Ocean Shipping Consultants (2007). Container Port Strategy, Emerging issues.

[17] Ocean Shipping Consultants (2007), Marketing of Container Terminals.

[18] T. Notteboom (2006), The Time Factor in Liner Shipping Services” , Maritime Economics \& Logistics, 8, (19-39)

[19] Veldman, S. and Vroomen B.(2007). A model of container port competition: an application for the transhipment market of the Mediterranean, IAME Conference Athens.

Received 15 November 2010

Revised 9 March 2011

Accepted 14 March 2011 